\title{
NASA debates 'privatizing' its space centres
}

Washington. Officials at the US National Aeronautics and Space Administration (NASA), faced with shrinking budgets and the prospect of laying off government scientists, are considering transferring some work to 'privatized' research institutes run by universities or other outside organizations.

Although the idea is still in its preliminary stages, NASA managers are planning to start talking to universities and consortia this week about the possibilities.

One approach would be to create institutes affiliated with particular NASA centres. Stanford University and the University of California, for example, already have ties with the Ames Research Center near San Francisco and might be interested in closer cooperation. Similarly, the Lunar and Planetary Institute, located adjacent to the Johnson Space Center outside Houston, Texas might expand its charter to become a centre for human exploration of space, incorporating both planetary science and life sciences.

Another option would be to look for a single organization - perhaps a consortium such as the Universities Space Research Association - that could manage the entire network of affiliated research centres "to give it more cohesion", says France Cordova, chief scientist at the space agency.

Many NASA scientists would welcome such a scheme. Most could probably continue working at their current centres, merely being paid from a university rather than directly from the government. But what they would gain in freedom from bureaucracy might be offset by the insecurity of living on government contracts.

The idea of privatizing research at the centres is discussed in a 17-page draft report by Cordova and the heads of NASA's three offices responsible for space science, microgravity and life sciences, and Earth science. The report was written in response one released last month by an internal NASA review panel, set up by administrator Dan Goldin and called the 'Red Team', that was intended to provoke debate on how the agency should be restructured.

Although the science managers say the new report "should in no way be construed as an official NASA "science plan," they take issue with some of the Red Team's suggestions and float several ideas of their own "to enlarge the dialogue".

Science at Ames could be privatized, they say, using as a model the Institutes of Geophysics and Planetary Physics (IGPP), operated at multiple sites by the University of California. They suggest that the Goddard Space Flight Center in suburban Washington DC should reduce its science managers and contractor scientists. And that the National Oceanic and Atmospheric Administration, which operates US weather satellites, might take over responsibility for data distribution from NASA's proposed Earth Observing System.

Beyond such specific recommendations, the draft report challenges certain basic premises of the Red Team report, such as the idea that considerable overlap exists in the science conducted at different NASA centres. "Redundant naming does not necessarily imply redundant capability," it says.

They point out, for example, that even though Johnson, Ames and the Jet Propulsion Laboratory (JPL) all do "planetary science", Ames focuses on planetary biology, Johnson on planetary materials and samples, and JPL on planetary geophysics and atmospheres.

The Red Team task force, which did not include any scientists, argued that each centre's mission should be narrowly focused. In contrast, the science officials support diversity and multidisciplinary research, and the conduct of certain types of research at more than one NASA location.

While the Red Team propose giving JPL responsibility for all basic space science not counting Earth science, which would go to Goddard - the science managers would amend that to "primary responsibility", and then only for planetary science.

JPL, owned and operated by the California Institute of Technology, is generally considered a good model for privatization. But giving JPL overall responsibility for NASAfinanced science programmes could create its own problems.

Last week, for example, the agency announced the winners of a competition for low-cost planetary missions in the 'Discovery' series. A Lockheed-Ames concept for a cut-rate ( $\$ 59$ million) mission to map the Moon and search for ice at its poles, dubbed the Lunar Prospector, was approved for launch in 1997. (Three more missions - to return cometary dust samples, to study the Venusian atmosphere, and to collect solar wind particles and return them to Earth were picked for further study.)

Although JPL scientists and engineers were involved in many of the 28 proposed Discovery concepts, NASA intends to award contracts equally to NASA centres, universities and private companies. If JPL managed the Discovery programme, it would have an inherent conflict of interest.

Even though the NASA science officials claim that privatization would offer benefits - and presumably savings - their report argues strongly that the agency should still maintain a core of staff scientists. "Credibility of internal science expertise, both basic and applied, is important to provide maximum support for external guest investigators and to assure NASA's critical capacity to act as a 'smart buyer'," they write.

Privatization would bring many uncertainties, not least whether it really would save money. Many agency scientists question whether JPL operates more cheaply than other centres. And NASA is not even certain how much money it needs to save.

Wesley Huntress, head of the office of space science, predicts that the spending power of his office will decline by 18 per cent between now and 2000. But that takes into account only cuts already made by President Bill Clinton to finance his proposed tax cut for the middle class. Congress has yet to suggest its own cuts.

But some kind of reorganization is inevitable. Goldin, has told his staff to brace for significant reductions in personnel, to be decided in a series of reviews over the next two months. Huntress told an advisory committee for Solar System science last week, that "this administrator is going to change the centres, period." Tony Reichhardt

\section{White House aide to quit policy office}

Washington. M. R. C. Greenwood (right), associate director for science at the White House Office of Science and Technology Policy (OSTP), is to leave the administration on 1 May to return to California to care for a friend who has breast cancer.

An accomplished researcher into the genetic causes of obesity, Greenwood is regarded in the science community as an effective liaison with the White House. She says she is "very sorry to be leaving".

As the only associate director at OSTP responsible for basic science - previous administrations had two, one for life sciences and one for physical sciences Greenwood has had a tough job fighting basic research's corner within a adminis-

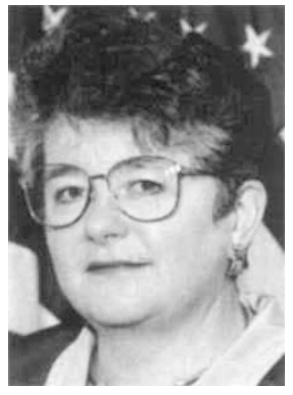

tration orientated to technology. But she successfully pushed through the administration's science policy document, Science in the National Interest, last August, and claims some of the credit for maintaining research funding level in Clinton's 1996 budget proposal. "I think we have a very respectable 1996 budget," she says. In May, Greenwood will return to her previous job as dean of graduate studies at the University of California at Davis.
Colin Macilwain 